
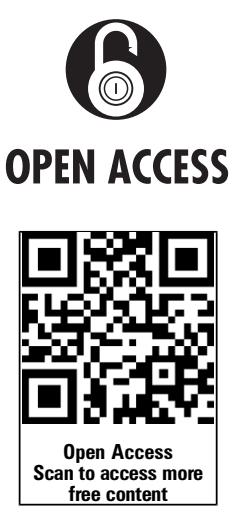

- Additional material is published online only. To view please visit the journal online (http://dx.doi.org/10.1136/ heartjnl-2015-308616).

For numbered affiliations see end of article.

Correspondence to Dr Marlous Hall, Senior Epidemiologist, Leeds Institute of Cardiovascular and Metabolic Medicine, MRC Bioinformatics Unit, Worsley Building, Level 11, Clarendon Way, University of Leeds, Leeds LS2 9JT, UK; m.s.hall@leeds.ac.uk

Received 29 August 2015 Revised 18 November 2015 Accepted 27 November 2015 Published Online First 6 January 2016

\section{SLinked}

- http://dx.doi.org/10.1136 heartjnl-2015-309094

\section{CrossMark}

To cite: Hall M, Laut $K_{\text {, }}$ Dondo TB, et al. Heart 2016;102:313-319.

\title{
Patient and hospital determinants of primary percutaneous coronary intervention in England, 2003-2013
}

\author{
M Hall, ${ }^{1} \mathrm{~K}$ Laut, ${ }^{1} \mathrm{~T}$ B Dondo, ${ }^{1}$ O A Alabas, ${ }^{1}$ R A Brogan, ${ }^{1,2}$ N Gutacker, ${ }^{3}$ \\ R Cookson, ${ }^{3}$ P Norman, ${ }^{4}$ A Timmis, ${ }^{5} \mathrm{M}$ de Belder, ${ }^{6}$ P F Ludman, ${ }^{7}$ C P Gale, ${ }^{1,2}$ \\ on behalf of the National Institute for Cardiovascular Outcomes Research (NICOR)
}

ABSTRACT

Objective Primary percutaneous coronary intervention (PPCI) for ST-elevation myocardial infarction (STEMI) is insufficiently implemented in many countries. We investigated patient and hospital characteristics associated with PPCl utilisation.

Methods Whole country registry data (MINAP, Myocardial Ischaemia National Audit Project) comprising PPCI-capable National Health Service trusts in England (84 hospital trusts; 92350 hospitalisations; 90489 patients), 2003-2013. Multilevel Poisson regression modelled the relationship between incidence rate ratios (IRR) of PPCl and patient and trust-level factors.

Results Overall, standardised rates of PPCI increased from $0.01 \%$ to $86.3 \%$ (2003-2013). While, on average, there was a yearly increase in $\mathrm{PPCl}$ utilisation of $30 \%$ (adjusted IRR $1.30,95 \% \mathrm{Cl} 1.23$ to 1.36), it varied substantially between trusts. PPCI rates were lower for patients with previous myocardial infarction $(0.95,0.93$ to 0.98$)$, heart failure $(0.86,0.81$ to 0.92$)$, angina $(0.96,0.94$ to 0.98$)$, diabetes $(0.97,0.95$ to 0.99$)$, chronic renal failure $(0.89,0.85$ to 0.90$)$, cerebrovascular disease $(0.96,0.93$ to 0.99$)$, age $>80$ years $(0.87,0.85$ to 0.90$)$, and travel distances $>30 \mathrm{~km}(0.95,0.93$ to 0.98$)$. PPCl rates were higher for patients with previous percutaneous coronary intervention $(1.09,1.05$ to 1.12$)$ and among trusts with $>5$ interventional cardiologists (1.30, 1.25 to 1.34), more visiting interventional cardiologists (1-5: 1.31, 1.26 to $1.36 ; \geq 6: 1.42,1.35$ to 1.49$)$, and a $24 \mathrm{~h}$, 7-days-a-week PPCI service $(2.69,2.58$ to 2.81$)$. Half of the unexplained variation in $\mathrm{PPCl}$ rates was due to between-trust differences.

Conclusions Following an 8 year implementation phase, PPCI utilisation rates stabilised at $85 \%$. However, older and sicker patients were less likely to receive PPCI and there remained between-trust variation in $\mathrm{PPCl}$ rates not attributable to differences in staffing levels.

Compliance with clinical pathways for STEMI is needed to ensure more equitable quality of care.

\section{INTRODUCTION}

Variation between and within countries in the adoption of evidence based care is a major global healthcare problem. ${ }^{1}$ ST-elevation myocardial infarction (STEMI) comprises $25-40 \%$ of all acute myocardial infarction cases in Europe and the USA, and represents one of the most common reasons for hospitalisation worldwide. $^{2-4}$ For its acute management, there is a Class 1 Level A treatment recommendation for primary percutaneous coronary intervention (PPCI) because it is associated with a relative risk reduction of death of approximately $37 \%$ over fibrinolytic therapy. ${ }^{5}$ However, studies report substantial inter-regional differences in its utilisation. ${ }^{6-11}$ It is not surprising that strategies to ensure its wider and faster diffusion have been at the forefront of international efforts to improve the quality and outcomes of cardiovascular care.

Thus far none of the studies investigating the diffusion of PPCI have incorporated whole healthcare systems or assessed patient-level and hospital-level data simultaneously. ${ }^{8}{ }^{12}$ Rather, they have been based on small samples, select cohorts, span only part of the implementation phase or have been limited through their use of non-contemporaneous, administrative or insurance-based databases. ${ }^{7}$ 13-15 This is particularly important because convenience sampling of only cases and centres with up-to-standard data may bias estimates or create uncertainty around the impact of clinical variables. In addition, earlier studies typically have been ecological in design - an approach which limits the interpretation of inferences about outcomes relating to individuals. ${ }^{89}$ As a result, the literature provides an uncertain picture of the relationship between patient-level and hospital-level characteristics and the diffusion of PPCI. Many countries do not yet provide PPCI as the treatment of choice for the emergency reperfusion of STEMI. ${ }^{16-20}$ Contemporary knowledge about the barriers and enablers of PPCI implementation will be essential to the future effective provision of nationwide services.

In the UK, continuous whole country data for STEMI and associated PPCI are collected through the Myocardial Ischaemia National Audit Project (MINAP) registry. This provides a unique opportunity to undertake large-scale phenotype- and intervention-specific research. To address the limitations of previous studies, for a clinically important cohort, we used MINAP data to investigate the diffusion of PPCI for STEMI across the National Health Service (NHS) in England. Specifically, the aims of this study were (1) to describe betweenhospital and temporal variation in standardised rates of utilisation of PPCI, and (2) to quantify patient-level and trust-level factors associated with its implementation. 


\section{METHODS}

\section{Setting and design}

Anonymised patient level data were obtained from the national heart attack register, MINAP. MINAP is a comprehensive clinical database of patients hospitalised with acute myocardial infarction, mandated by the Department of Health for all hospitals in England and Wales. ${ }^{21}$ Data are collected prospectively at each hospital, electronically encrypted and transferred online to a central database. Data entry is subject to routine error checking and a mandatory annual validation exercise. MINAP is overseen by a multi-professional steering group and the National Institute for Cardiovascular Outcomes Research (NICOR) executive. ${ }^{22}$ Each MINAP entry provides patient demographic data and clinical details of the patient journey across 122 data items. NICOR, which includes MINAP, has support under section 251 of the NHS Act 2006 to use patient information for medical research without consent (Ref: NIGB: ECC 1-06 (d)/2011). Ethical approval was not required under NHS research governance arrangements.

Individuals were eligible for inclusion in our study if they were admitted directly to a PPCI-capable hospital (a hospital with the infrastructure and skills to offer PPCI) in England with STEMI between 1 January 2003 and 30 June 2013 and were aged $\geq 18$ years. Inter-hospital transfers were not included in the analysis, nor hospitals performing only sporadic PPCI procedures. STEMI diagnoses were identified via the discharge diagnosis as recorded in MINAP. Patient baseline characteristics were age, gender, ethnicity, comorbidities, previous medical history, and socioeconomic status (based on the 2010 English Indices of Multiple Deprivation, and categorised from most deprived (5) to least deprived (1)). Patients were selected as having received PPCI according to their initial reperfusion strategy. To be eligible for PPCI, patients met the following criteria: clinical presentation suggestive of myocardial infarction with symptom duration of $\leq 12 \mathrm{~h}$ and ST-segment elevation of $\geq 0.1 \mathrm{mV}$ in at least two contiguous leads, or $\geq 0.2 \mathrm{mV}$ in $\mathrm{V} 1-\mathrm{V} 3$, or presumed newonset left bundle branch block on electrocardiography.

The characteristics of hospitals for each year of study, including number of interventional cardiologists, number of visiting interventional cardiologists, type of PPCI service offered ('24/7' or ' 9 to 5' service), teaching status, and hospital size (measured as total number of hospital beds) were obtained from the British Cardiovascular Intervention Society (BCIS) survey (personal communication with PFL). In addition, publicly available hospital trust data concerning the total available bed days and number of occupied bed days by consultant main specialty were obtained from NHS England (http://www.england.nhs.uk/ statistics/statistical-work-areas/bed-availability-and-occupancy/ bed-data-overnight/) from 2003 to 2013. Although these latter data were not available for individual hospitals within a trust, among our cohort of hospitals there were only three trusts which contained more than one hospital providing PPCI services (in these cases the trust characteristics were applied to both hospitals). Euclidean (straight line) distances from each patient's residence to the nearest trust with onsite PPCI facilities were derived from patients' and trusts' postcodes, translated into Cartesian coordinates (see online supplementary appendix section 1). All trust data were linked to MINAP data through the NICOR analytical team before releasing pseudonymised patient and hospital identification data for the analyses.

\section{Outcome}

The primary endpoint was PPCI utilisation, calculated as the rate of PPCI per hospital out of the total number of STEMI hospitalisations per hospital. For patients with multiple PPCIs across multiple hospitalisations, all were included in the calculation.

\section{Statistical analysis}

Baseline characteristics were summarised as numbers and percentages, means and SDs, and medians and IQRs for categorical, normally distributed and non-normally distributed continuous data, respectively. To analyse temporal trends of PPCI utilisation, age-and sex-standardised rates of PPCI per 100000 STEMI hospitalisations and $95 \%$ CIs were summarised by year of hospitalisation for PPCI.

We built a series of multilevel Poisson regression models (which accounted for the clustering of patients within trusts) to quantify the degree to which patient characteristics and trust-level factors were associated with annual hospital PPCI utilisation, with the number of STEMI hospitalisations as the offset term. Initially, univariable models were fitted and subsequently multivariable models built by incrementally adding variables which had significant associations with PPCI utilisation to a base model that comprised age, sex and year as well as a random intercept for each trust. The Index of Multiple Deprivation quintile did not contribute significantly to the base model and was, therefore, omitted. Initially models focused on patient characteristics and then on trust-level characteristics to assess their relative impact upon PPCI utilisation. Model estimates were presented as incidence rate ratios (IRRs) which are interpreted as the linear increase or decrease in trust PPCI utilisation over the study period after adjusting for confounding factors. All explanatory variables were introduced as fixed effects, except year, which was included as a random effect to allow for variation in the rate of change of PPCI utilisation over time between trusts. To assess the degree of variation in PPCI utilisation rates attributed to the trust level (and not explained by the model), we obtained an approximation to the intraclass correlation coefficient (ICC) from a multilevel linear regression model which used PPCI rates as the outcome (see online supplementary appendix section 1).

The extent of patients with missing data for case mix variables and confounders was evaluated and managed by multiple imputation. To undertake this, we imputed 10 datasets using chained equations before analysis and pooled estimates using Rubin's rules across the imputed datasets. Imputation models were congruent to analysis models and included the outcome variable following methods used previously for MINAP data (see online supplementary appendix table S1). To check the accuracy and consistency of the imputation process, imputed data were compared to complete case analysis (see online supplementary appendix table S2). The Poisson model was checked for overdispersion by comparison with a negative binomial model (see online supplementary appendix table S3).

Multiple imputation was performed in R V.3.1.2 (The $\mathrm{R}$ Project for Statistical Computing, cran.r-project.org) and all further statistical analyses were performed in Stata MP V.13 (Stata Corp, Texas, USA). Values of $\mathrm{p}<0.05$ were considered to be statistically significant and all tests were two sided.

\section{RESULTS}

We identified 300868 individuals with STEMI admitted to hospitals in the UK. We excluded 23332 (7.8\%) records from hospitals outside England, and 95666 (34.5\%) records for individuals in non-PPCI capable hospitals. Of the remaining 181870 patients with a discharge diagnosis of STEMI, across 84 trusts, there were a total of 92350 (50.8\%) hospitalisations 


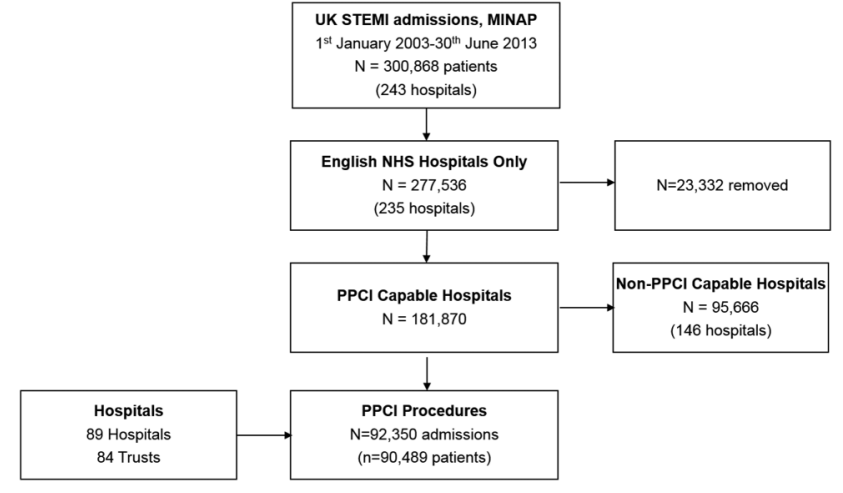

Figure 1 Consort diagram of exclusions of the Myocardial Ischaemia National Audit Project (MINAP) dataset. PPCl, primary percutaneous coronary angiography; ST, ST-elevation myocardial infarction.

for 90489 patients for which PPCI was performed. There were 1859 (1\%) patients who had multiple hospitalisations (figure 1).

The mean \pm SD age was $63.7 \pm 13.2$ years; $26.4 \%$ of patients were female and $14 \%$ had diabetes. Across the study years, the mean age increased from 60.1 to 63.8 years (table 1 ). There was a decrease in the proportion of patients belonging to the most deprived group (56.7-22.4\%), and a corresponding increase in patients belonging to the least deprived group (3.3-18.4\%). Moreover, we found that the proportion of patients who received PPCI and lived further away from the PPCI centre increased from no cases living $>30 \mathrm{~km}$ away in 2003/2004 to $18.3 \%$ of cases living $>30 \mathrm{~km}$ away in $2011 / 2013$. The median number of trust beds remained stable over the study period (843.5 in $2005 / 2007$ to 837 in $2011 / 2013$ ), while the mean number of cardiologists increased (1.2 in $2005 / 2007$ to 4.9 in 2011/2013). The number of trusts performing PPCI '24/7' (24 h service 7 days a week) increased from $7.2 \%$ in $2005 / 2007$ to $57 \%$ in $2011 / 2013$.

\section{Variation}

There was an increase in the utilisation of PPCI over the 10 year study period, with the overall age and sex standardised rate of PPCIs out of all STEMI hospitalisations increasing significantly from $0.01 \%$ (95\% CI $0.001 \%$ to $0.06 \%$ ) in 2003 to $86.3 \%$ (95\% CI $79.5 \%$ to $94.2 \%$ ) in 2013 (figure 2). On average, there was a year-on-year increase in PPCI utilisation of $30 \%$ (IRR $1.30,95 \%$ CI $1.23 \%$ to $1.36 \%$ ) after adjustment for patient and hospital characteristics. The rate of change varied significantly between hospitals (random effect parameter for year $\mathrm{SD}=0.22,95 \% \mathrm{CI} 0.19$ to 0.26 ). The rate of PPCI utilisation ranged from a $4 \%$ increase to a threefold increase (IRR $1.04,95 \%$ CI 1.23 to 1.36 ; and IRR 3.17 , 95\% CI 1.23 to 1.36) for the central $95 \%$ of trusts. The rate of change varied over the study period, with an annual increase in PPCI utilisation of $63 \%$ occurring in 2006/2008 (IRR 1.63, 95\% CI 1.57 to 1.71 ) followed by a $9 \%$ increase in $2009 / 2011$ (IRR 1.09 , $95 \%$ CI 1.08 to 1.09 ) and no further increase in $2012 / 2013$ (IRR 1.01, 95\% CI 0.98 to 1.03 ).

\section{Determinants of utilisation}

There were significant associations between PPCI utilisation and year of procedure, age, previous myocardial infarction, angina, PCI, chronic renal failure, heart failure, diabetes, cerebrovascular disease, distance to hospital, number of hospital beds, number of interventional cardiologists, number of visiting cardiologists, and the availability of a 24/7 PPCI service (table 2). PPCI utilisation was significantly lower for patients with previous myocardial infarction (IRR $0.95,95 \%$ CI 0.93 to 0.98 ), heart failure (IRR $0.86,95 \%$ CI 0.81 to 0.92 ), angina (IRR $0.96,95 \%$ CI 0.94 to 0.98), diabetes (IRR $0.97,95 \%$ CI 0.95 to 0.99 ), chronic renal failure (IRR $0.89,95 \%$ CI 0.85 to 0.94 ), cerebrovascular disease (IRR $0.96,95 \%$ CI 0.93 to 0.99 ), aged $>80$ years (IRR 0.87 , $95 \%$ CI 0.85 to 0.90 ), and travel distances $>30 \mathrm{~km}$ (IRR 0.95 , 95\% CI 0.93 to 0.98 ). PPCI utilisation was significantly higher for patients with previous PCI (IRR 1.09, 95\% CI 1.05 to 1.12), among trusts with $>5$ interventional cardiologists (IRR 1.30, 95\% CI 1.25 to 1.34 ), more visiting cardiologists (1-5 consultants: IRR $1.31,95 \% 1.26$ to $1.36 ;>6$ consultants: IRR 1.42 , 1.35 to 1.49 ), and a $24 / 7$ service (IRR 2.69 , 95\% CI 2.58 to 2.81). Larger hospitals had lower rates of PPCI ( $>1000$ vs $<700$ beds, IRR 0.92 , $95 \%$ CI 0.88 to 0.97 ). We found that $49 \%$ of the unexplained variation in PPCI utilisation was due to differences between trusts (ICC 0.49).

\section{DISCUSSION}

This is the first patient-level single country analysis of the temporal implementation of PPCI for the emergency management of STEMI. Over a 10 year study period, we found evidence for an 8 year implementation phase that achieved overall high rates of PPCI per STEMI coverage across England. However, this occurred after a lag of several years. At the end of the study period we found persisting wide variation in rates of PPCI at hospitals and evidence that older and sicker patients were less likely to receive PPCI. While PPCI utilisation was significantly associated with patient-level and trust-level characteristics, one half of the unexplained variation in PPCI utilisation was due to between-hospital factors.

To date, international registry data have shown that implementation of reperfusion therapy for STEMI is insufficient. Earlier studies described how England differed from other European countries, with much slower PPCI adoption, ${ }^{23}$ and greater between provider variation in 30 day mortality. ${ }^{24}$ This study adds more detail-revealing significant provider variation in emergency care. Our findings are surprising since the acute treatment of STEMI in a healthcare setting of universal coverage should result in low inequalities in access. Moreover, for STEMI there is little controversy or ambiguity concerning the effectiveness of PPCI (STEMI is more readily diagnosable than NSTEMI and the majority of patients are hospitalised), and the demand for hospitalisation and treatment of STEMI is closely determined by its incidence.

Provider variation was large during the early PPCI implementation phase-with greater uniformity later. Such diffusion patterns are seen where there is a rapid improvement in treatments or where the range of treatment options has been enhanced, ${ }^{8} 91325$ as in the UK with the transition from fibrinolysis to PPCI. Yet, we identified between-provider variation at the end of the study, when across the health system the majority of STEMI patients received PPCI. Following the implementation phase, between-provider variation in guideline-indicated care should be minimal, and is likely to impact directly on population health outcomes. ${ }^{13} 26$

Variation in healthcare utilisation rates may reflect differences in population need for healthcare-with more services needed in areas of higher demand. Our study exploited rich and representative population panel data including individual-level health measures as well as socioeconomic background information, and temporal and spatial population data. To the contrary, we found PPCI rates were lower at hospitals with a higher proportion of patients who were elderly, diabetic, and with chronic renal and 
Table 1 Patient characteristics by period of admissions to hospital in England, 2003-2013

\begin{tabular}{|c|c|c|c|c|c|}
\hline \multirow{2}{*}{$\begin{array}{l}\text { Patient demographics, history } \\
\text { and cardiac status }\end{array}$} & \multicolumn{5}{|c|}{ Period of admission to hospital } \\
\hline & Total $(n=90498)$ & $2003-2004(n=30)$ & $2005-2007(n=4299)$ & $2008-2010(n=35000)$ & $2011-2013(n=51169)$ \\
\hline Age, years & $63.7(13.2)$ & $60.1(13.2)$ & $63.0(13.0)$ & $63.6(13.2)$ & $63.8(13.2)$ \\
\hline Female & $23776(26.4)$ & $7(23.3)$ & $1119(26.1)$ & $9286(26.6)$ & $13364(26.3)$ \\
\hline \multicolumn{6}{|l|}{ Ethnicity } \\
\hline Caucasian & $71631(90.0)$ & $17(77.3)$ & $2999(83.2)$ & $27241(90.6)$ & $41374(90.2)$ \\
\hline Other & $7941(10.0)$ & $5(22.7)$ & $714(16.8)$ & $2836(9.4)$ & $4496(9.8)$ \\
\hline \multicolumn{6}{|l|}{ Deprivation (IMD) } \\
\hline 1 (Least deprived) & $15368(17.3)$ & $1(3.3)$ & $550(13.2)$ & $5587(16.2)$ & $9230(18.4)$ \\
\hline 2 & $16250(18.3)$ & $1(3.3)$ & $625(15.0)$ & $6014(17.5)$ & $9610(19.1)$ \\
\hline 3 & $17730(19.9)$ & $3(10.0)$ & 797 (19.1) & $6675(19.4)$ & $10255(20.4)$ \\
\hline 4 & $18031(20.3)$ & $8(26.7)$ & $952(22.8)$ & $7180(20.8)$ & $9891(19.7)$ \\
\hline 5 (Most deprived) & $21556(24.2)$ & $17(56.7)$ & $1258(30.1)$ & $9007(26.1)$ & $11274(22.4)$ \\
\hline Ever smoked & $33240(66.9)$ & $13(82.6)$ & $1630(67.1)$ & $12920(67.5)$ & $18677(66.4)$ \\
\hline Diabetes & $11580(14.0)$ & $4(13.8)$ & $593(14.4)$ & $4188(13.2)$ & 6795 (14.5) \\
\hline Hypertension & $33645(42.9)$ & $10(90.9)$ & $1672(46.7)$ & $12883(43.6)$ & $19080(42.2)$ \\
\hline Dyslipidaemia & $25195(33.0)$ & $11(91.7)$ & 1249 (36.9) & $9826(34.3)$ & $14109(31.9)$ \\
\hline Family history of $C A D$ & $25885(36.9)$ & 0 & $11221(39.4)$ & $10328(39.1)$ & $14336(35.2)$ \\
\hline Previous angina & $9683(12.6)$ & 0 & $510(15.1)$ & $4047(13.9)$ & $5126(11.5)$ \\
\hline Previous MI & $9507(6.7)$ & $2(6.7)$ & $500(13.2)$ & 3799 (12.8) & $5255(11.7)$ \\
\hline Previous $\mathrm{PCl}$ & $5933(7.6)$ & $1(3.3)$ & $299(7.9)$ & $2320(7.9)$ & $3313(7.4)$ \\
\hline Previous CABG & $1877(2.4)$ & $1(3.3)$ & $97(2.5)$ & $754(2.6)$ & $1025(2.3)$ \\
\hline Chronic heart failure & 995 (1.3) & 0 & $60(1.8)$ & $336(1.2)$ & $599(1.3)$ \\
\hline Cerebrovascular disease & $3492(4.6)$ & $2(66.7)$ & $147(4.4)$ & $1353(4.7)$ & $1990(4.5)$ \\
\hline Renal failure & $1607(2.1)$ & 0 & $81(2.4)$ & $644(2.2)$ & $882(2.0)$ \\
\hline Peripheral vascular disease & $2195(2.9)$ & $3(75.0)$ & $123(3.8)$ & $830(2.9)$ & $1239(2.8)$ \\
\hline Chronic lung disease & $8068(10.5)$ & 0 & $342(10.5)$ & $3030(10.5)$ & $4696(10.5)$ \\
\hline \multicolumn{6}{|l|}{ Distance to hospital in $\mathrm{km}$} \\
\hline $0-5$ & $17421(19.6)$ & $10(33.3)$ & $1449(34.8)$ & 7535 (21.9) & $8427(16.8)$ \\
\hline $6-15$ & $33321(37.4)$ & $19(63.4)$ & $1829(43.9)$ & $13942(40.4)$ & $17531(34.9)$ \\
\hline $16-29$ & $24060(27.0)$ & $1(3.3)$ & $596(14.3)$ & $8330(24.2)$ & $15133(30.1)$ \\
\hline+30 & $14189(15.9)$ & 0 & $294(7.1)$ & $4686(13.6)$ & $9209(18.3)$ \\
\hline \multicolumn{6}{|l|}{ Trust characteristics $(n=84)$} \\
\hline \multicolumn{6}{|l|}{ Total number of beds } \\
\hline$<700$ & $214(31.4)$ & - & $69(31.1)$ & $74(32.2)$ & $71(30.9)$ \\
\hline 700-999 & $246(36.1)$ & - & 79 (35.6) & 78 (33.9) & $89(38.7)$ \\
\hline$\geq 1000$ & $222(32.5)$ & - & $74(33.3)$ & 78 (33.9) & $70(30.4)$ \\
\hline \multicolumn{6}{|l|}{ Number of acute and general beds } \\
\hline$<700$ & $292(43.7)$ & - & $112(51.4)$ & 89 (39.9) & $91(39.9)$ \\
\hline 700-999 & $216(32.3)$ & - & $60(27.5)$ & $71(31.8)$ & $85(37.3)$ \\
\hline$\geq 1000$ & $161(24.1)$ & - & $46(21.0)$ & $63(28.3)$ & $52(22.8)$ \\
\hline \multicolumn{6}{|c|}{ Number of in-house interventional cardiologists } \\
\hline None & $208(28.8)$ & - & $178(75.7)$ & $24(9.8)$ & $6(2.5)$ \\
\hline $1-5$ & $320(44.4)$ & - & $39(16.6)$ & $144(59.0)$ & $137(56.6)$ \\
\hline$>5$ & $193(26.8)$ & - & $18(7.7)$ & $76(31.2)$ & $99(40.9)$ \\
\hline \multicolumn{6}{|c|}{ Number of visiting interventional cardiologists } \\
\hline None & $432(59.9)$ & - & $203(86.4)$ & $124(50.8)$ & $105(43.4)$ \\
\hline $1-5$ & $199(27.6)$ & - & $21(8.9)$ & $80(32.8)$ & $98(40.5)$ \\
\hline$>5$ & $90(12.5)$ & - & $11(4.7)$ & $40(16.4)$ & $39(16.1)$ \\
\hline 24/7 PPCI service & $261(36.2)$ & - & $17(7.2)$ & $106(43.4)$ & $138(57.0)$ \\
\hline Teaching status & $327(45.4)$ & - & $107(45.5)$ & $110(45.1)$ & $110(45.5)$ \\
\hline
\end{tabular}

CABG, coronary artery bypass graft surgery; CAD, coronary artery disease; IMD, index of multiple deprivation; MI, myocardial infarction; PCl, percutaneous coronary intervention; PPCI primary $\mathrm{PCl}$.

heart failure. This 'risk-treatment paradox' has been described for other cardiovascular diseases and contrasts with the absolute risk of a life-threatening complication from an evidence based therapy being unlikely to exceed the survival benefit when applied in high-risk populations. ${ }^{27} 28$ Utilisation of PPCI did not appear to be influenced by area deprivation.
While age and comorbid status contributed to PPCI utilisation, almost half of the unexplained variation in PPCI use was at the hospital level. Supply factors, such as numbers of cardiologists and availability of a $24 \mathrm{~h}, 7$-days-a-week PPCI service were strong determinants of PPCI utilisation. Others have also shown that provider variation is mainly associated with the 


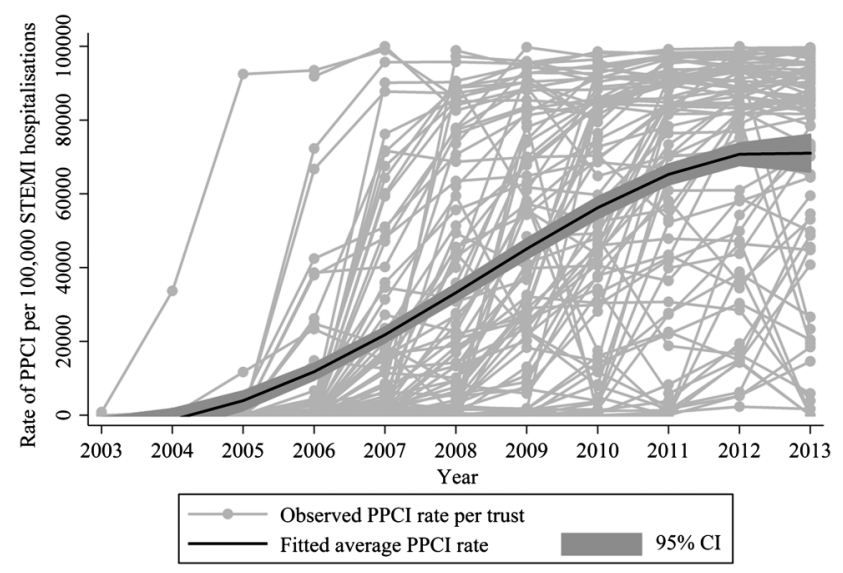

Figure 2 Observed and fitted average rate of primary percutaneous coronary intervention (PPCI) in England from 2003 to 2013. medical care systems and less with regional differences in disease incidence. ${ }^{25}$ Since PPCI is highly dependent on the availability of specialist resources, our findings are not surprising. $^{29} 30$ Notably the regulation of specialist capacity to perform medical procedures, with the availability of catheterisation laboratories (supplier-induced demand), is a strong determinant of technology use. ${ }^{8} 929$ Our study reveals that universal healthcare coverage and evidence for the benefits of a new technology associated with significant improvements in care for a wide sector of the population does not guarantee similar utilisation rates for treatment across a nation. Indeed, our observation of between-trust variation in PPCI use suggests an opportunity to further increase the utilisation of PPCI services and, ultimately, reduce premature cardiovascular deaths. This is particularly pertinent as, a priori, national implementation of PPCI across the NHS was based on a Department of Health directive and funding aiming for equitable PPCI

Table 2 Unadjusted and adjusted IRRs with 95\% Cls assessing variation in utilisation of PPCI in England, 2003-2013

\begin{tabular}{|c|c|c|c|c|}
\hline & \multicolumn{2}{|l|}{ Unadjusted } & \multicolumn{2}{|l|}{ Adjusted } \\
\hline & IRR $(95 \% \mathrm{Cl})$ & p Value & IRR $(95 \% \mathrm{Cl})$ & $\mathrm{p}$ Value \\
\hline Year & $1.28(1.27$ to 1.28$)$ & $<0.001$ & $1.30(1.23$ to 1.36$)$ & $<0.001$ \\
\hline \multicolumn{5}{|l|}{ Age } \\
\hline$<55$ & Ref & & Ref & \\
\hline $55-64$ & 0.97 (0.96 to 0.99$)$ & $<0.001$ & 1.00 (0.98 to 1.01$)$ & 0.731 \\
\hline $65-79$ & 0.93 (0.92 to 0.95$)$ & $<0.001$ & 0.99 (0.97 to 1.01$)$ & 0.117 \\
\hline $80+$ & 0.83 (0.81 to 0.85$)$ & $<0.001$ & 0.87 (0.85 to 0.90$)$ & $<0.001$ \\
\hline Male gender & 1.06 (1.05 to 1.08$)$ & $<0.001$ & $1.02(1.00$ to 1.03$)$ & 0.044 \\
\hline \multicolumn{5}{|l|}{ Distance to hospital in $\mathrm{km}$} \\
\hline$<6$ & Ref & & Ref & \\
\hline $6-15$ & 1.15 (1.13 to 1.18$)$ & $<0.001$ & 1.02 (0.99 to 1.04$)$ & 0.078 \\
\hline $16-29$ & $1.32(1.28$ to 1.35$)$ & $<0.001$ & 1.03 (1.00 to 1.05$)$ & 0.025 \\
\hline $30+$ & $1.28(1.25$ to 1.32$)$ & $<0.001$ & 0.95 (0.93 to 0.98 ) & 0.001 \\
\hline Family history of chronic heart disease & 1.21 (1.19 to 1.23$)$ & $<0.001$ & 1.01 (1.00 to 1.03 ) & 0.085 \\
\hline Previous acute MI & $0.92(0.90$ to 0.94$)$ & $<0.001$ & 0.95 (0.93 to 0.98$)$ & $<0.001$ \\
\hline Previous chronic cardiac failure & $0.76(0.72$ to 0.81$)$ & $<0.001$ & 0.86 (0.81 to 0.92$)$ & $<0.001$ \\
\hline Previous angina & $0.86(0.84$ to 0.88$)$ & $<0.001$ & 0.96 (0.94 to 0.98$)$ & 0.001 \\
\hline Diabetes mellitus & 1.00 (0.98 to 1.02$)$ & 0.860 & 0.97 (0.95 to 0.99$)$ & 0.001 \\
\hline Chronic renal failure & 0.90 (0.86 to 0.95$)$ & $<0.001$ & 0.89 (0.85 to 0.94$)$ & $<0.001$ \\
\hline Previous PCl & 1.11 (1.09 to 1.14$)$ & $<0.001$ & 1.09 (1.05 to 1.12$)$ & $<0.001$ \\
\hline Previous CABG & 0.93 (0.89 to 0.97$)$ & $<0.001$ & 0.96 (0.92 to 1.01$)$ & 0.130 \\
\hline Cerebrovascular disease & $0.94(0.91$ to 0.97$)$ & $<0.001$ & 0.96 (0.93 to 0.99$)$ & 0.012 \\
\hline Smoker & $1.04(1.03$ to 1.06$)$ & $<0.001$ & 1.01 (0.99 to 1.02$)$ & 0.205 \\
\hline \multicolumn{5}{|l|}{ Total number of beds at trust } \\
\hline$<700$ & Ref & & Ref & \\
\hline 700-999 & 0.93 (0.89 to 0.98 ) & 0.003 & 0.99 (0.95 to 1.04$)$ & 0.802 \\
\hline $1000+$ & 0.75 (0.71 to 0.79 ) & $<0.001$ & 0.92 (0.88 to 0.97 ) & 0.001 \\
\hline \multicolumn{5}{|l|}{ Number of interventional cardiologists } \\
\hline$<5$ & Ref & & Ref & \\
\hline$>5$ & 4.10 (4.00 to 4.21$)$ & $<0.001$ & 1.30 (1.25 to 1.34$)$ & $<0.001$ \\
\hline \multicolumn{5}{|c|}{ Number of visiting interventional cardiologists } \\
\hline 0 & Ref & & Ref & \\
\hline $1-5$ & 3.46 (3.37 to 3.56$)$ & $<0.001$ & 1.31 (1.26 to 1.36$)$ & $<0.001$ \\
\hline $6+$ & 4.22 (4.09 to 437$)$ & $<0.001$ & $1.42(1.35$ to 1.49$)$ & $<0.001$ \\
\hline \multicolumn{5}{|l|}{$\mathrm{PPCl}$ service } \\
\hline Daytime only (09:00-17:00) & Ref & & Ref & \\
\hline $24 \mathrm{~h}$ service 7 days a week & 7.19 (6.99 to 7.39$)$ & $<0.001$ & 2.69 (2.58 to 2.81$)$ & $<0.001$ \\
\hline Teaching status (university hospital) & $1.27(1.19$ to 1.36$)$ & $<0.001$ & $1.01(0.93$ to 1.10$)$ & 0.809 \\
\hline
\end{tabular}


delivery across hospital trusts. To address this shortfall, our findings provide evidence to suggest that PPCI-capable hospitals must have an 'all-comers' policy that is compliant with clinical guidelines, provide a $24 \mathrm{~h}$, 7-days-a-week service, be adequately staffed with specialists, and not be so large that there are diseconomies of scale. Future research is needed to ascertain whether the availability of specialist facilities and regulation of capacity explains the large and significant between-hospital variation which was not attributable to case mix and staffing levels.

\section{Limitations}

This study analysed patient-level data aiming specifically to not introduce an ecological fallacy; it does, however, have limitations. While MINAP data entry is subject to routine error checking and a mandatory annual data validation exercise, the analyses were dependent upon the accuracy of the data. We were unable to include patients in non-PPCI capable hospitals, within which we identified a small proportion of patients who did receive PPCI $(n=8862 ; 9 \%)$. We controlled for a number of patient risk factors deemed clinically relevant, which are assumed to be exogenous to the hospital, and can be derived from MINAP. However, we do not claim that this set of control variables is exhaustive and the issues of additional confounding are apparent. Even so, a strength of our study is that we used detailed registry data to control for patients' comorbid conditions, thus making our inferences more robust than using routinely available administrative or survey sample data. Finally, observational analyses such as these reveal important associations, but cannot prove causation.

Key messages

What is already known on this subject?

- ST-elevation myocardial infarction (STEMI) is a common and major cause of premature death. Timely primary percutaneous intervention (PPCI) is the preferred mode of revascularisation because it is associated with significantly improved outcomes.

- There is variation in the level of use of PPCI which is associated with supply and demand factors, but this has not been investigated at the level of the provider using patient-level data within a single healthcare system.

What might this study add?

- While the rates of $\mathrm{PPCl}$ increased rapidly $(0.01 \%$ to $86.3 \%)$, the entire implementation took 8 years. Sicker patients were less likely to receive PPCI by $5 \%, 4 \%$ and $3 \%$ for those with previous myocardial infarction, angina and diabetes, respectively. We found evidence for wide variation between hospitals in their utilisation of PPCl, and although medical staffing levels were associated with this variation, it did not account for all of the between-hospital variation.

How might this impact on clinical practice?

- Our observation of between-trust variation in PPCI use suggests an opportunity to further increase the utilisation of $\mathrm{PPCl}$ services and, ultimately, reduce premature cardiovascular deaths. Compliance with agreed clinical pathways for patients presenting with STEMI is needed to ensure more equitable quality of care.

\section{Conclusions}

This nationwide 10 year study of the uptake and utilisation of PPCI for STEMI found evidence for an 8 year implementation phase that achieved overall high rates of PPCI per STEMI hospitalisation. However, at the end of the implementation phase, there remained wide variation in hospital rates of PPCI. In particular, older and sicker patients were less likely to receive PPCI. While the use of PPCI was significantly associated with patient-level characteristics, there remained significant variation due to hospital-specific factors that were not attributable to differences in medical staffing levels. Compliance with agreed clinical pathways for patients presenting with STEMI is needed to ensure more equitable quality of care.

\section{DISCLOSURES}

All authors have completed the ICMJE uniform disclosure form at http://www.icmje.org/coi_disclosure.pdf and declare no support from any organisation for the submitted work; no financial relationships with any organisations that might have an interest in the submitted work in the previous 3 years; and no other relationships or activities that could appear to have influenced the submitted work.

\section{Author affiliations}

${ }^{1}$ Leeds Institute of Cardiovascular and Metabolic Medicine, University of Leeds, Leeds, UK

${ }^{2}$ York Teaching Hospital NHS Foundation Trust, York, UK

${ }^{3}$ Centre for Health Economics, University of York, York, UK

${ }^{4}$ School of Geography, University of Leeds, Leeds, UK

${ }^{5} \mathrm{NIHR}$ Biomedical Research Unit at Barts Health, Queen Mary University, London, UK

${ }^{6}$ The James Cook University Hospital, South Tees Hospitals NHS Foundation Trust, Middlesbrough, UK

${ }^{7}$ Queen Elizabeth Hospital, Birmingham, UK

${ }^{8}$ National Institute for cardiovascular Outcomes Research (NICOR), University College, Institute of Cardiovascular Science, London, UK

Acknowledgements The extract from the MINAP registry was provided through the MINAP Academic Group, NICOR, UCL, London. We acknowledge all the hospitals in England and Wales for their contribution of data to MINAP. We thank Dr Peter Jepsen; Department of Hepatology and Gastroenterology, Aarhus University Hospital, Aarhus, Denmark for analytical assistance. He did not receive compensation for his assistance.

Contributors $\mathrm{MH}, \mathrm{KL}$ and $\mathrm{CPG}$ led on the design and analysis of the research and drafted the manuscript. OA and TBD provided substantial input into the preliminary data analysis, including imputation of data. NG and RC contributed to the design of the work and interpretation of the data and statistical analysis. AT, PFL, RAB and $\mathrm{MdB}$ provided input to the clinical interpretation of data and to the overall design of the study. PFL and PN provided additional data for inclusion in the study (hospital characteristics data and geographical data, respectively) and contributed to interpretation of these data. All authors made critical revisions and provided intellectual content to the manuscript, approved the final version to be published, and agreed to be accountable for all aspects of the work. CPG and MH are the guarantors for this study.

Funding MH and TD are funded by the British Heart Foundation (Project Grant PG/ 13/81/30474). CPG is funded by the National Institute for Health Research (NIHR-CTF-2014-03-03) as Associate Professor and Honorary Consultant Cardiologist. RC is funded by the National Institute for Health Research (NIHR-SRF-2014-06-015) as a Senior Research Fellow and Professor of Health Economics. The Myocardial Ischaemia National Audit Project (MINAP) is commissioned by the Health Quality Improvement Partnership (HQIP) as part of the National Clinical Audit and Patient Outcomes Programme (NCAPOP). The researchers worked independently from the funders and all authors, external and internal, had full access to all of the data (including statistical reports and tables) in the study and can take responsibility for the integrity of the data and the accuracy of the data analysis.

\section{Competing interests None declared.}

Provenance and peer review Not commissioned; externally peer reviewed.

Transparency statement The lead author (CPG) affirms that the manuscript is an honest, accurate, and transparent account of the study being reported; that no important aspects of the study have been omitted; and that any discrepancies from the study as planned have been explained. 
Open Access This is an Open Access article distributed in accordance with the terms of the Creative Commons Attribution (CC BY 4.0) license, which permits others to distribute, remix, adapt and build upon this work, for commercial use, provided the original work is properly cited. See: http://creativecommons.org/ licenses/by/4.0/

\section{REFERENCES}

1 World Health Organization. Tracking University Health Coverage: First Global Monitoring Report. France: WHO, 2015. http://apps.who.int/iris/bitstream/10665/ 174536/1/9789241564977_eng.pdf?ua=1 (accessed 29 Jul 2015).

2 O'Gara PT, Kushner FG, Ascheim DD, et al. ACCF/AHA guideline for the management of ST-elevation myocardial infarction: executive summary: a report of the American College of Cardiology Foundation/American Heart Association Task Force on Practice Guidelines: developed in collaboration with the American College of Emergency Physicians and Society for Cardiovascular Angiography and Interventions. Catheter Cardiovasc Interv 2013;82:E1-27.

3 Jernberg T, Attebring MF, Hambraeus K, et al. The Swedish web-system for enhancement and development of evidence-based care in heart disease evaluated according to recommended therapies (SWEDEHEART). Heart 2010;96: 1617-21.

4 Roger VL, Go AS, Lloyd-Jones DM, et al. Heart disease and stroke statistics-2012 update: a report from the American Heart Association. Circulation 2012;125:e2-220.

5 de Boer SP, Barnes EH, Westerhout CM, et al. High-risk patients with ST-elevation myocardial infarction derive greatest absolute benefit from primary percutaneous coronary intervention: results from the Primary Coronary Angioplasty Trialist versus thrombolysis (PCAT)-2 collaboration. Am Heart J 2011;161:500-7.e1.

6 Krumholz HM, Chen J, Rathore SS, et al. Regional variation in the treatment and outcomes of myocardial infarction: investigating New England's advantage. Am Heart J 2003;146:242-9.

7 Laskey W, Spence N, Zhao X, et al. Regional differences in quality of care and outcomes for the treatment of acute coronary syndromes: an analysis from the Get With The Guidelines Coronary Artery Disease Program. Crit Pathw Cardiol 2010;9:1-7.

8 Laut KG, Gale CP, Lash TL, et al. Determinants and patterns of utilization of primary percutaneous coronary intervention across 12 European countries: 2003-2008. Int J Cardiol 2013;168:2745-53.

9 Laut $K G$, Gale $C P$, Pedersen $A B$, et al. Persistent geographical disparities in the use of primary percutaneous coronary intervention in 120 European regions: exploring the variation. Eurolntervention 2013;9:469-76.

10 Patel $A B, T u$ JV, Waters NM, et al. Access to primary percutaneous coronary intervention for ST-segment elevation myocardial infarction in Canada: a geographic analysis. Open Med 2010;4:e13-21.

11 Ferreira-Pinto LM, Rocha-Gonçalves F, Teixeira-Pinto A. An ecological study on the geographic patterns of ischaemic heart disease in Portugal and its association with demography, economic factors and health resources distribution. BMJ Open 2012;2: pii:e000595.

12 Laut KG, Pedersen $A B$, Lash TL, et al. Barriers to implementation of primary percutaneous coronary intervention in Europe. European Cardiology 2011;7:108-12.

13 Jernberg $T$, Johanson P, Held C, et al. Association between adoption of evidence-based treatment and survival for patients with ST-elevation myocardial infarction. JAMA 2011;305:1677-84.
14 Ko DT, Krumholz HM, Wang Y, et al. Regional differences in process of care and outcomes for older acute myocardial infarction patients in the United States and Ontario, Canada. Circulation 2007;115:196-203

15 Kolte D, Khera S, Aronow WS, et al. Regional variation across the United States in management and outcomes of ST-elevation myocardial infarction: analysis of the 2003 to 2010 nationwide inpatient sample database. Clin Cardio 2014;37:204-12.

16 Smith FGD, Brogan RA, Alabas 0, et al. Comparative care and outcomes for acute coronary syndromes in Central and Eastern European transitional countries: a review of the literature. Eur Heart J Acute Cardiovasc Care 2014;4:537-54.

17 Widimsky P, Wijns W, Fajadet J, et al. Reperfusion therapy for ST elevation acute myocardial infarction in Europe: description of the current situation in 30 countries. Eur Heart J 2010;31:943-57.

18 Li J, Li X, Wang Q, et al. ST-segment elevation myocardial infarction in China from 2001 to 2011 (the China PEACE-Retrospective Acute Myocardial Infarction Study): a retrospective analysis of hospital data. Lancet 2015;385:441-51.

19 Dharma S, Andriantoro H, Dakota I, et al. Organisation of reperfusion therapy for STEMI in a developing country. Open Heart 2015;2:e000240.

20 Kook HY, Jeong MH, Oh S, et al. Current trend of acute myocardial infarction in Korea (from the Korea Acute Myocardial Infarction Registry from 2006 to 2013). Am J Cardiol 2014;114:1817-22.

21 Herrett E, Smeeth L, Walker L, et al. The Myocardial Ischaemia National Audit Project (MINAP). Heart 2010;96:1264-7.

22 Gale CP, Weston C, Denaxas S, et al. Engaging with the clinical data transparency initiative: a view from the National Institute for Cardiovascular Outcomes Research (NICOR). Heart 2012;98:1040-3.

23 Kristensen SD, Laut KG, Fajadet J, et al. Reperfusion therapy for ST elevation acute myocardial infarction 2010/2011: current status in 37 ESC countries. Eur Heart J 2014;35:1957-70.

24 Chung S-C, Sundström J, Gale CP, et al. Comparison of hospital variation in acute myocardial infarction care and outcome between Sweden and United Kingdom: population based cohort study using nationwide clinical registries. BMJ 2015;351: h3913.

25 Wennberg JE. Tracking Medicine: A Researcher's Quest to Understand Health Care. Oxford University Press, 2010.

26 Terkelsen CJ, Sørensen JT, Maeng M, et al. System delay and mortality among patients with STEMI treated with primary percutaneous coronary intervention. JAMA 2010;304:763-71.

27 Alter DA, Ko DT, Newman A, et al. Factors explaining the under-use of reperfusion therapy among ideal patients with ST-segment elevation myocardial infarction. Eur Heart J 2006;27:1539-49.

28 Bhatt DL, Roe MT, Peterson ED, et al. Utilization of early invasive management strategies for high-risk patients with non-ST-segment elevation acute coronary syndromes: results from the CRUSADE Quality Improvement Initiative. JAMA 2004;292:2096-104.

29 Black N, Langham S, Petticrew M. Coronary revascularisation: why do rates vary geographically in the UK? J Epidemiol Community Health 1995;49: 408-12.

30 Goodacre S, Sampson F, Carter A, et al. Evaluation of the National Infarct Angioplasty Project. National Co-ordinating Centre for NHS Service Delivery and Organisation R\&D (NCCSDO) 2008:169. 